\title{
Managing Current Climate Variability Can Ensure Water Security Under Climate Change
}

\author{
Mike Muller
}

\section{Contents}

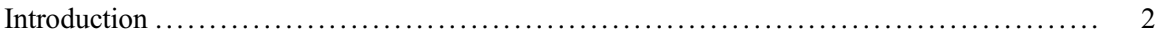

Characterizing Hydrological Variability and Climate Change Impacts $\ldots \ldots \ldots \ldots \ldots \ldots \ldots . \quad 4$

Current Hydrological Variability ............................................. 4

"Easy" Versus "Difficult" Hydrologies ........................................ 4

Climate Change Science Has Helped to Characterize Climate Variability ............. 5

Predictions of Climate Change Impacts on Hydrological Processes .................. 6

Tools to Manage "Dynamic Stationarity" ........................................ 8

Right Tools for the Right Job: But which Job? ............................... 8

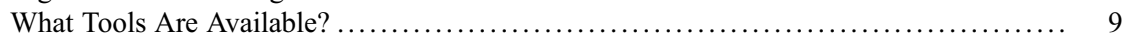

Methods to Determine the Scale of Maximum Probable Events .................... 10

Right Tools in the Right Place: At the Right Time ............................... 10

From Tools to their Application: Some Case Studies .............................. 11

Cape Town's Day Zero Drought: A Failure to Acknowledge Risks of

Climate Variability ............................................... 12

Mombasa, Kenya: Climate-Resilient Designs Constrained by Institutions
and Finance $\ldots \ldots \ldots \ldots \ldots \ldots \ldots \ldots \ldots \ldots \ldots \ldots \ldots \ldots \ldots \ldots \ldots \ldots \ldots \ldots \ldots \ldots \ldots \ldots \ldots \ldots \ldots \ldots \ldots \ldots \ldots \ldots \ldots \ldots \ldots \ldots \ldots \ldots$

Windhoek, Namibia: A Climate Secure Source Using Groundwater as Storage .......... 14

Beira, Mozambique: Sea Level Rise Will Compound Existing Challenges ............. 16

Polihali Dam and the Integrated Vaal River System: Sustaining a "Problemshed" ....... 16

Zambezi River Coordination: Drought Risks, Discount Rates, and Batoka Dam

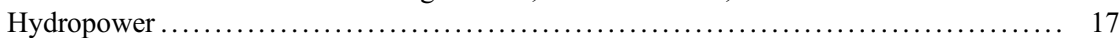

This chapter was previously published non-open access with exclusive rights reserved by the Publisher. It has been changed retrospectively to open access under a CC BY 4.0 license and the copyright holder is "The Author(s)". For further details, please see the license information at the end of the chapter.

M. Muller $(\bowtie)$

Wits School of Governance, University of the Witwatersrand, Johannesburg, South Africa

e-mail: mike.muller@wits.ac.za 


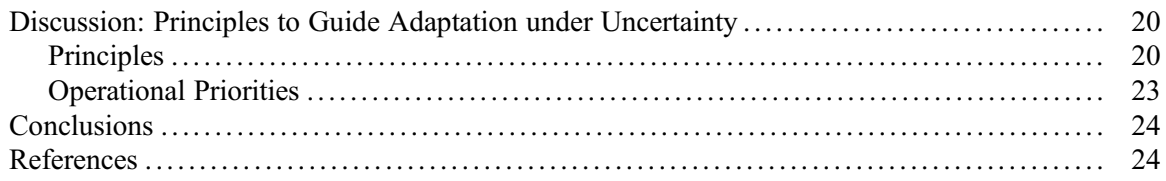

\section{Abstract}

Water resources will be significantly impacted upon by climate change, and these impacts will be transmitted to the many sectors and services dependent on them. The nature, extent, and timing of these impacts remain uncertain, but the long lifetime of water infrastructures requires that their planning, development, and operations should be resilient to climate changes. An effective approach is to focus on the management of current climate variability as it relates to water, which strengthens the ability of communities and countries to foresee, manage, and adapt to the impacts of longer-term climate change on water-related activities. This approach is illustrated by cases from Southern and Eastern Africa.

Current "stationary" stochastic methods of hydrological analysis can still be used under assumptions of a "dynamic stationarity" although more regular updating of hydrological data will be required. Methodologies to evaluate economic dimensions of risk reduction introduce additional uncertainties but may help decision-makers to understand the risks and opportunities. Diversification of sources and sequencing of resource development pathways are helpful strategies to adapt to climate change but must ensure that risks affecting different sources are not correlated. Attention must also be given to demand-side interventions in order to reconcile supply and demand, and these perspectives must be shared with social, economic, and political actors to ensure that strategies are communicated, understood, and supported by the wider community.

\section{Keywords}

Water resources - Climate adaptation - Climate variability and change $\cdot$ Water supply $\cdot$ Hydropower $\cdot$ Hydrology $\cdot$ Stationarity $\cdot$ Utility economics $\cdot$ Public finance

\section{Introduction}

There is international agreement at the UNFCCC about the need for collective action to address the likely impacts of global warming on human societies. One response has been to encourage all sectors of society to identify and implement actions that can help adapt to the emerging impacts of climate change and work to mitigate its drivers.

Water resources and the services dependent on them are an integral part of the climate system (Chahine 1992). Because of this, the managers of water resource systems and of the services that depend on them must develop appropriate responses 
to the potential impacts of climate change (Strzepek et al. 2011).The African continent is considered to be particularly vulnerable to these impacts both because of their magnitude and because African societies have less physical, financial, and human resources available to address these impacts.

A further challenge is that the impacts of climate change on water resources are local, diverse, and not well-characterized. Unlike the general global warming trend, for which there is robust evidence that is consistent with the predicted impact of anthropogenic activities, direct evidence of significant changes in hydrological variables is not nearly as strong and consistent.

For example, it appears that at a global level, precipitation is increasing (Adler et al. 2017). However, models predict increases in drought frequency over significant areas due to warming (Ukkola et al. 2020) although empirical evidence in support of this is limited (Hegerl et al. 2019) and predictions are based on various definitions of drought.

While warming trends are a direct result of anthropogenically induced atmospheric changes that act through a single dominant mechanism at global level, the impacts on the main hydrological processes - evaporation, precipitation, runoff, and infiltration - are secondary and tertiary effects that are further influenced by a wide variety of mechanisms at a local, regional, and global level. So while there is only a limited increase in global precipitation averages, there are more extensive regional variations and substantial changes in parameters such as rainfall intensity (Trenberth 2011) which, coupled with the impact of warmer temperatures on aridity, lead to changes in tertiary variables such as stream flow.

The likely impact of climate change on hydrological processes is generally still too uncertain to make it possible for water resource planners and managers to identify locally specific adaptive measures. So climate change models and predictions cannot usually guide well-founded planning and operational decisions although they do help to suggest the boundaries for extreme events.

However, policy-makers like the UN High-Level Panel on Water want to know what impacts global warming will have on water systems and how they will be dealt with. It is suggested that an appropriate response is to continue to build on the great strength of best practice in water resource science and management, which is its ability to characterize and manage climatic variability. This requires that the approaches used move beyond the assumptions of a stationary hydrology and can accommodate a changing climate (Brekke et al. 2009).

Yet water managers are already responding to climate change through their management of current climate variability. However, to make this case convincingly, they must demonstrate that current methodologies are adequate for the task. To address this in an African context, this chapter:

- Characterizes the "difficult hydrologies" that pose particular challenges in Africa and shows how climate change science has helped to understand the climate variability inherent in those hydrologies 
- Considers some analytical tools that are used to manage under assumptions of "stationary hydrology" and whether they can be adapted reflect "dynamic stationarity"

- Presents six African cases that illustrate how the management of current variability is supporting adaptation to potential climate change impacts

Drawing on lessons from these cases, some conclusions are drawn about approaches that, while deriving from current hydrologies, are more explicitly adaptive and will be resilient in an uncertain future.

A supply-side focus is taken because the availability of water is most directly impacted upon by climate change. The demand side is equally important and challenging, but human behavior and social institutions that guide it merit separate consideration. The reconciliation of supply and demand remains the ultimate technical goal of water management.

\section{Characterizing Hydrological Variability and Climate Change Impacts}

\section{Current Hydrological Variability}

Climate warming due to anthropogenic activity is a global phenomenon, but its specific impacts on water resources depend on local conditions, including current climatic variability. Water resource managers need to characterize that current variability if they are to manage it successfully. This characterization provides the foundation from which to review the impacts of climate change on water resources and the hydrological cycle.

The primary driver of the hydrological cycle is the interaction between incoming solar energy and the large mass of water in the oceans. However, water managers necessarily focus on rainfall, whose duration, intensity, and distribution in space and time drive other elements of the hydrological cycle: surface runoff, infiltration, and evapotranspiration. The interaction between these variables then determines the stream and groundwater flows, whose magnitude and fluctuation are the "raw material" of water resource management.

\section{"Easy" Versus “Difficult" Hydrologies}

From this perspective, climate creates the hydrological context both for the "natural" biosphere and for human communities and their activities that depend on it. But it is the variability of climate as much as the average values of its component elements that determines whether the resulting hydrological context enables communities to establish and sustain productive and congenial environmental niches. Grey and Sadoff (2007) echo previous investigators, suggesting that climatic variability has 
been a determining factor in the social and economic development of different societies.

A nation's hydrology will clearly affect the level of institutions and investment required to achieve water security. The absolute levels of water resource availability, its inter- and intraannual variability and its spatial distribution, coupled with the demand for water, will largely determine the institutions and the types and scale of infrastructure needed to manage, store and move the resource. The resilience of the structure of the economy to water shocks, together with societal resilience and risk aversion will also be determinants of the level of investment required for specific countries to reach the tipping point of water security.

A distinction is drawn between "easy" and "difficult" hydrological legacies. An "easy" hydrology is characterized by adequate rainfall with little variation between seasons and years. Such hydrologies sustain predictable perennial river flows, supported by reliable groundwater availability. The predictability of the hydrology and its relative consistency makes the management of water for different purposes relatively easy, facilitating the conceptualization and operation of infrastructure as well as the establishment of the rules that govern the entitlements and obligations of water users.

Regions with difficult hydrologies require stronger institutions as well as higher levels of physical investments in order to support basic activities such as agriculture or even simply to meet domestic needs. One reason that many poor countries remain poor is that they could not accumulate the resources needed to achieve the water security on which higher levels of development depend. As summarized, difficult hydrologies include:

- Absolute water scarcity

- Low-lying lands subject to severe flood risk

- Markedly seasonal rainfall which requires the storage of water

- High inter-annual climate variability, where unpredictable risks require over-year storage

- A combination of extreme intra-annual seasonality and inter-annual variability

This crude distinction between difficult and easy hydrologies highlights the need to understand existing climate variability before focusing on the potential impacts of climate change. At the least, water managers need to understand the key systems that drive their local climate and the extent of uncertainty about the resulting rainfall patterns and related hydrological parameters in order to identify sustainable strategies for their water resource development and management.

\section{Climate Change Science Has Helped to Characterize Climate Variability}

Paradoxically, climate change science must build on an understanding of "normal" climate variability in order to attribute any phenomenon to climate change rather 
than simply a "normal" extreme. So while the Sahel droughts of the 1970s/1980s were often attributed to climate change, evidence of subsequent "rainfall recovery" suggests that this was simply long-cycle climate variability, perhaps aggravated by land- and water-use changes (Sidibe et al. 2018).

There are similar debates about changes in the intensity and frequency of the occasional and unpredictable tropical storms, an important factor in the hydrology of Southeastern Africa (Malherbe et al. 2012). Claims that those storms were becoming more frequent and intense due to global sea warming have subsequently been challenged, since the 35-year-long satellite data set on which they were based is relatively short; it is now suggested that tropical storm formation was mostly influenced by long-cycle variations in the phenomena such as ENSO and the Indian Ocean Dipole (Chan 2006).

The hypothesis that storm frequency is increasing due to global warming is also not supported by later studies, and it is even suggested that south of the tropic of Capricorn, where storm numbers were expected to increase, they have actually decreased (Pillay and Fitchett 2019). However, the debate continues, and there is continuing uncertainty about likely changes in cyclone frequency and their regional prevalence (Knutson et al. 2020).

Variations in lake levels are also often attributed to climate change with recent fluctuations in Africa's lakes Victoria, Chad, and others specifically cited, although with acknowledgment that human influence is also a factor. Yet many of Africa's shallower African lakes are known for their variable levels (Conway 2005).

Lake levels are arguably more useful as indicators of the impact of climate variability than climate change since they are determined by the climate over the lakes and their catchment areas as well as the impact of human activity. A recent global review found that background climate variation due to multi-decadal climatic oscillations such as ENSO accounted for $58 \%$ of the variation in lake levels; a further $10 \%$ variation was due to normal seasonal effects. It was concluded that apparent trends attributed to anthropogenic activities were often exaggerated by this "normal" background variation and that due attention should be given to background climate variation before claiming climate change impacts (Kraemer et al. 2020).

These examples show that it is necessary to correct the current popular (and academic) discourse in Africa and elsewhere which sees water managers, policymakers and political heads attribute many extreme events to climate change, although climate records show that neither the event nor its frequency of occurrence is inconsistent with patterns evident in the historical record.

\section{Predictions of Climate Change Impacts on Hydrological Processes}

There is no doubt that global warming is already having a variety of impacts on hydrological systems. However, while some impacts are known, others are uncertain and are likely to vary significantly from place to place. These uncertainties need to be better understood and communicated by practitioners to policy-makers and publics. 
Some climate change impacts are directly related to the impact of anthropogenic warming on specific hydrological variables. While the water-holding capacity of air increases with temperature, this does not necessarily mean that global rainfall will increase at the same rate. However, recent work concludes that observations confirm modeling predictions that rainfall does increase with rising temperatures and that this is associated with a change in the intensity and timing of rainfall events (Giorgi et al. 2019). It is also evident that there are regional changes in the distribution of rainfall although uncertainties remain about these important relationships (Herold et al. 2017).

Similarly uncertain is the impact of warming climates on soil moisture, a hydrological variable that underpins the agricultural activities on which human societies depend and which are, by far, the largest direct "users" of water. Aridity, the ratio between precipitation and potential evapotranspiration, is expected to impact on surface water runoff, a critical process for water management.

Aridity might be expected to increase with global warming since evapotranspiration is greater under higher temperatures, but this is not universal. Globally, some arid areas (in the Americas) have become wetter, whereas previously semi-humid areas (particularly in Asia) became drier. And significant discrepancies are reported between model predictions and direct observations leading to warnings that the general conclusion that climate change will result in "overall drier conditions across the globe" might be "at least partly misleading" (Greve et al. 2019).

The discrepancies are attributed, in part, to the fact that the increased $\mathrm{CO} 2$ that drives global warming also changes the vegetation types, which may use water more efficiently. As the authors explain, ".....changes in atmospheric $\mathrm{CO} 2$ break the existing correlation between hydrology and ecology by changing the water use efficiency of photosynthesis."

These issues are important for sub-Saharan Africa where bush encroachment is reducing the animal carrying capacity of semiarid rangelands although human changes in land use are at least as important as climate change in driving this process (Venter et al. 2018). What is important for water managers is that changes in aridity and land cover will change the relationship between rainfall and runoff, potentially affecting water resource availability (Zareian et al. 2017) and leading to significant stream flow reductions.

These processes are complex, and outcomes will be determined by locally specific conditions. The proportion of rainfall that reaches a stream or recharges groundwater is determined by the amount of rainfall, its intensity and duration, prior soil moisture, as well as temperature and land cover. One response to this complexity has been to apply catchment models, developed to provide guidance on rainfallrunoff relationships. But these models are based on historical circumstances that may not be appropriate under new conditions of climate and land cover. In Australia, historical rainfall-runoff models might produce valid results under future climates, but only if rainfall changes were relatively modest (Vaze et al. 2010). In Europe while runoff correlates closely with soil moisture, relations with precipitation and temperature are weaker, and a recent survey identified a better understanding of 
runoff dynamics as a priority "unsolved question" for hydrologists (Blochl et al. 2019).

\section{Tools to Manage "Dynamic Stationarity"}

There will clearly be continuing uncertainty about climate change-driven hydrological trends due to the wide diversity of water resource contexts in which hydrological processes occur. Furthermore, substantial "normal" variability will often mask smaller climate change impacts.

It is thus appropriate for practitioners to focus explicitly on managing climate variability. This is not an argument for "stationarity" (the assumption that climate is not changing) nor a suggestion that water resource planners should ignore warmingrelated climate change. Rather, it is a practical response. While it has long been accepted that hydrological analysis must reflect the changing climate (Moss and Tasker 1987), tools developed under assumptions of "stationary" hydrology may yet be used under the new conditions of hydrological dynamism (Milly et al. 2008).

\section{Right Tools for the Right Job: But which Job?}

Water resource practitioners use a wide variety of tools to guide their decisions, but their tools' limitations and their adaptation to address changing climates must be considered in the context of the functions that they support. These include:

- Monitoring and information management, about both resource availability and resource use

- Planning, to determine trends in resource availability and use and to inform options, identification, and analysis

- Allocation, to ensure that water use achieves society's objectives within the constraints imposed by the resource itself

- Development of infrastructure, to make water available for use as well as to maintain its quality

- Sustainable operation of complex infrastructure systems

- Protection of the environmental condition of the resource

The timeframe and nature of guidance that will be required vary dramatically between the functions, and the tools provided have to be appropriate for the purpose:

- Planning requires projections of the yield available from different sources and systems, often over very long time horizons (50-100 years in the case of large systems) with indications of assurance derived from assumptions about the variability of the resource. While climate change is clearly relevant over long time horizons, planning does not necessarily commit to specific actions until firm decisions are taken. 
- Infrastructure must optimize output based on design requirements and be guided by estimates of the magnitudes of extreme events that could lead to failure. The long lifetime of water resource infrastructure limits the subsequent adoption of alternative options and enforces a degree of "path dependence" (Hüttl et al. 2016).

- System operation needs short-term (seasonal up to 5 years) guidance to maintain supply assurances, while flood routing requires real-time models.

- Water allocations to users must be informed by "normal" availability of supply but allow adjustment for contingencies such as drought as well as to cater for future climate change (which is often missing from legal frameworks despite earlier warnings (Trelease 1977)).

In summary, water resource managers must be enabled to (i) make reasonable predictions about the potential yield of sources and systems over time; (ii) provide guidance based on variability parameters to support system restrictions during drought; (iii) provide robust, conservative information about risks posed by extreme flood events; and (iv) operate their systems to achieve reasonably predictable outputs under variable conditions.

\section{What Tools Are Available?}

Simple rainfall-runoff models, developed to support urban drainage design and flood estimation, were of limited value in larger catchments, particularly in the absence of information on rainfall characteristics. The development of stochastic techniques to provide rainfall and river flow estimates and guide reservoir operation greatly expanded the analytical capabilities of water planners.

The complex relationships between hydrological variables, the diversity of situations, and the volume of data involved meant that key concepts could only be translated into tools for practitioners when modern computing power became available. The Harvard Water Program developed many methodologies using "synthetic" or stochastic hydrologies (Maass et al. 1962) not just to solve hydrological questions but also to support the economic optimization of water projects.

There is now a wide variety of hydrological tools and methodologies that have been applied. Loucks and van Beek's extensive compendium (2017) (Loucks and Van Beek 2017) links the technicalities of methodologies and models to their application in real-world planning problems. These are supported by new streams of data from remote sensing although this does not fully compensate for the decay in the physical observation network (World Bank 2018a). The challenges posed by climate change have led to suggestions that a new Harvard Water Program is needed.

To address some of the functions outlined above, tools used include the following:

\section{Stochastic Methodologies to Estimate Flow and Rainfall}

The stochastic methodologies described above have transformed water management. When applied with the requisite caution and skill, they enable planners to extend 
short flow or rainfall records to provide reasonable estimates of mean and extreme flows at different levels of assurance as well as to provide synthetic "records" for ungauged rivers and catchments. Stochastic models lend themselves to testing hypotheses about the potential impacts of changes in rainfall patterns and (given the computing power now available) can generate and test large numbers of synthetic sets of rainfall and flow to determine sensitivities to different climatic circumstances. Climate change does, however, mean that the value of such methodologies depends on the regular updating of the data on which they are based.

\section{Catchment-Scale Rainfall-Runoff Models to Support Yield and Operations}

Catchment-based rainfall-runoff models are also widely used to estimate the potential yield of different sources and systems and to support operations ranging from drought management to flood routing. The rainfall-runoff relationships can be extrapolated from known areas to similar, poorly gauged catchments to predict stream flows and guide water management more generally (Vogel 2017). Such models can provide a structured basis for yield estimation taking account of new flow and rainfall records and changes in land use (see, for instance, the South African framework which has evolved over the past 60 years) (Bailey and Pitman 2016). While the maintenance of these models requires consistent investment in both physical data collection and subsequent processing, they provide an invaluable basis for the planning, expansion, and operation of large systems. The evolution of the planning and operational models for South Africa's Vaal River System (see below) provides an instructive insight.

\section{Methods to Determine the Scale of Maximum Probable Events}

A particular challenge in designing large water resource infrastructure is to ensure that it is resilient to the most extreme event "likely." The primary determinant of the scale of the "probable maximum flood" is the probable maximum precipitation. Since the objective in determining the PMF is to identify a worst-case scenario, this is a case where the application of multiple climate models can be useful since there will be a strong argument for selecting the highest value generated (Gangrade et al. 2018). For these kinds of events, in large catchments, catchment dynamics and landuse changes have less influence.

\section{Right Tools in the Right Place: At the Right Time}

One consequence of the huge diversity in the local hydrological regimes on which societies' water supplies depend is that technical paradigms that work well in one context have often been promoted inappropriately in others (Woodhouse and Muller 2017). Aid-dependent African countries have been particularly vulnerable to this trend because approaches promoted often reflected donor country conditions or the 
educational system in rich countries simply assumes that its approach is globally appropriate (Briscoe 2010). The promotion of a reliance on "green infrastructure" rather than built infrastructure is a recent incarnation of this trend (Muller et al. 2015).

While environmentally focused approaches may be appropriate in temperate developed countries, they do not help communities under more challenging climates in Africa, Asia, and Latin America where populations and economies are growing rapidly. Aside from the socioeconomic conditions, there are dramatically different topographies, geologies, and climatic conditions of aridity and often greater interseasonal and inter-annual variability of temperature and precipitation.

There are stark contrasts in the physical context for water resource management even in developed regions, between Europe's temperate northern regions and its Mediterranean south and temperate northeastern USA, its humid, subtropical southeast, giving way to semiarid southwest. In each region, the character of water resources and thus the options available to address water resource challenges are different, and different tools of analysis will be used. A further key differentiator is the human and financial resources that can be brought to bear: "With increasingly 'difficult' hydrology, the level of institutional refinement and infrastructure investment needed to achieve basic water security becomes significantly greater than in temperate (and less variable) climates" (Grey and Sadoff 2007).

There must be appropriate responses to current variability and uncertainty before the particular challenges of climate change can be addressed. For many countries, the priority problems relate to present water insecurity, not future climate change. As the cases below show, responses to, for instance, urban water shortages are unlikely to be much altered by considerations of climate change.

When solutions proposed could increase future costs and risks, climate change considerations become important. What is most immediately important in (relatively) poor communities and countries that do not have acceptable levels of water security is the efficient and effective use of scarce resources to deal with current variability. Many recent water "crises" popularly attributed to climate change have been the consequence of a failure to prepare for current variability. Opposition to long-run investment decisions (Matalas 1997) aggravates immediate problems, with limited evidence of long-run negative consequences. Often, it reflects policy preferences rather than any well-founded evidence of harm or risk (Muller et al. 2015)

\section{From Tools to their Application: Some Case Studies}

Water management practitioners have available a plethora of tools of increasing complexity and cost (as measured in human resources, finances, and data) to help them to manage climate variability. Yet the extent to which these tools can help water managers to address the challenges of climate change is limited. How should the practitioners proceed?

This is more than a technical issue. Water is managed to achieve a wide variety of societal goals, and water managers operate under a range of technical, financial, as 
well as social and political constraints and produce a variety of economic benefits. Tools to analyze the performance of water projects are also needed to assess their financial risks and economic returns in many different contexts.

A new mining or agricultural business may require a secure water supply. Governments seek to reduce poverty and promote greater economic inclusion by providing irrigation water, enabling poor farming communities to improve their productivity. Power utilities seek competitive, reliable energy sources. Urban managers, concerned about the disruptive effects of water restrictions due to drought, want to enhance water security.

Water managers and their institutions must be able to respond authoritatively to both political decision-makers and their wider communities. Most stakeholders will be concerned about the risks that climate change is assumed to pose and will need some assurances that these have been adequately addressed.

In this section, a number of cases from Southern and Eastern Africa are presented that show how water managers have used available tools to achieve specific water management objectives by addressing climate variability and concerns about climate change. The cases locate climate variability and change challenges in a wider socioeconomic context and consider whether the approaches adopted have increased resilience to potential climate change impacts. Three of the cases were included in a World Bank study of resilience in African infrastructure which aimed to develop processes that support "robust decision-making" (RDM) (Cervigni et al. 2015).

\section{Cape Town's Day Zero Drought: A Failure to Acknowledge Risks of Climate Variability}

Between 2015 and 2018, droughts in the extreme south west of South Africa saw the City of Cape Town suffering serious water restrictions. It was widely reported that the city faced a "Day Zero" on which its water supplies would "run out." These events, copiously documented, were widely attributed to climate change.

However, over the previous decade, there had been repeated recommendations from national technical and planning agencies calling for investments to augment, by 2015, the supply capacity of the Western Cape Water Supply System (WCWSS), on which the city depends (Muller 2018). These recommendations were based on a long-term WCWSS strategy study, informed by a hydrologically based system model that had successfully been used for two decades.

The model's projections of the supplies reliably available from existing sources were set against projections of water demand in a "reconciliation" process. This identifies any requirement for increased supply, the primary driver being the needs of Cape Town's growing population. The interventions proposed were sequenced on a "least-unit-cost" basis. Records of meetings in 2013 and 2014 suggest that the city believed that its efforts to manage demand had constrained growth and that further supply expansion would only be required in 2022 .

Even before the drought ended, implementation had begun of infrastructure projects that had earlier been rejected - including water reuse and groundwater 
development as well as additional surface water. Consideration is also being given to a large desalination installation which could be used during drought periods.

The vulnerabilities of the WCWSS are now obvious. The system depends on rainfall over a small $\left(800 \mathrm{~km}^{2}\right)$ area of mountain catchments supplying dams whose storage is less than 2 years of "normal" use. Climate change dynamics are also under review. Cape Town lies at the edge of dominant rain-producing weather systems and has long been identified as an area vulnerable to climate change-driven rainfall reductions (Archer et al. 2019). From an adaptation perspective, the questions are whether the shift of weather system is permanent and the nature of an appropriate adaptation response.

The city's new postcrisis strategy (Cape Town 2019) acknowledges continued dependence on surface water for $75 \%$ of its supplies for at least the next decade, while alternative sources such as reuse, groundwater, and desalination are developed to provide a greater proportion of supplies in the future.

Climate uncertainty is specifically addressed. The program aims to increase the assurance of supply from the system from $98 \%$ to $99.5 \%$ but acknowledges that there might be "a step change in rainfall due to climate change .... If this turns out to be the case, the programme will be both accelerated and expanded."

The strategy also acknowledges that water investments must provide regular supplies during periods of low rainfall: "All water schemes provide insurance against periods of low rainfall, which may become more frequent and more severe as a result of climate change." It recognizes that expensive supplies from reuse and desalination will not be used all the time but concludes: “. . this will not have been wasteful expenditure. The future is uncertain, and the cost of very severe restrictions is much higher than the cost of insuring against this likelihood."

In this regard, the city's strategy now explicitly addresses climate change. But rather than placing reliance on forecasting future availability, it seeks to increase reliability (through infrastructure investment originally proposed to address variability) to "buy time" for implementing rapid interventions such as desalination if required.

\section{Mombasa, Kenya: Climate-Resilient Designs Constrained by Institutions and Finance}

Greater Mombasa, Kenya's second largest city, had a population of approximately three million people in 2018. It is Kenya and the East African region's primary port and is also a center for international beach tourism which complements the country's inland game park complexes.

Water supply is deeply deficient. Water requirements are estimated to be in the region $250 \mathrm{Ml} /$ day, but the city is in a permanent state of water crisis, able to provide less than $30 \%$ of this potential amount (Foster et al. 2020). Small supplies from local coastal aquifers are at the limit of their available capacity and face problems of salinization. The city's primary supply comes from two distant groundwater sources, the Mzima Springs (200 km away) and Baricho (100 km). 
Unusually, local surface water sources had not been tapped although the need for a new source had already been identified in the early 1990s. The preferred augmentation project, now in preparation, is a dam on the small, local Mwache River.

All five projects in the 2015 World Bank infrastructure resilience study (Cervigni et al. 2015) which included Mwache faced considerable uncertainty about future rainfall under climate change. In none was there even a consensus on whether it would be higher or lower than present-day averages, let alone by how much. This was a particular concern for Mombasa whose rainfall derives from a combination of systems since $61 \%$ of the 121 climate future scenarios generated for Mwache showed lower safe yields than the present-day design assumptions.

The World Bank study took a measured response to this systemic uncertainty. It distinguished between project sensitivity to climate change and project vulnerability; sensitivity refers to the possible reduction in physical "output," while vulnerability considers the impact on economic return. In this view, even if a project's performance is potentially sensitive to climate change, "the project's economic worthiness is not necessarily in question." This would include cases where the project was robust to a high degree of climate variability "and in the bargain, to climate change" so that its benefits and revenues would meet the required criteria.

"It is thus important to distinguish between climate sensitivity and vulnerability" emphasized the report, noting that both sensitivity and vulnerability would depend on the metrics used to assess performance and that factors other than climate change, such as price and demand, could be equally important.

For Mwache, although limited hydrological information was available, the design chosen was considered to have low climate risk since the river flow is considerably in excess of supply requirements and there is a low risk that the dam will not meet its target yield (World Bank 2018b).

Funding has not yet been approved, not due to climate change risks but because the financial and institutional arrangements for the dam's management must still be resolved. Kenya's 2010 Constitution makes water supply the responsibility of local counties. But Mombasa's current supplies come from other counties, and the Mwache Dam itself will be built in a neighboring county.

Current proposals are to establish a regional institution that would manage all the different sources into a single system, providing bulk supplies to the major centers of four counties. This would help to address climate risks since linking different sources into a single system would increase its resilience to climate variability, maintaining supplies even if one source in the system fails. But achieving financial agreement between four counties and national government is proving to be more difficult than finding a climate-resilient dam design.

\section{Windhoek, Namibia: A Climate Secure Source Using Groundwater as Storage}

Namibia's capital Windhoek, high in the center of the arid and sparsely populated country, was established in 1892 by German colonists, attracted by the secure source 
of water from local springs. This groundwater resource served the growing settlement well until the 1960s when, after a series of dry years, it became obvious that additional supplies were needed.

In 1968, a "direct potable reuse" plant was built that treats wastewater for reinjection into the city's main supply. Subsequently expanded, it can now provide $20 \%$ of the city's potable supply. An ambitious longer-term plan envisaged a phased regional scheme, the Eastern National Water Carrier (ENWC), drawing from Southern Africa's third largest river, the Okavango, on Namibia's border with Angola, $700 \mathrm{~km}$ from Windhoek. The full project has not yet been completed, but growing demand has been met by intermediate interventions, including the development of new groundwater sources on the ENWC route. Throughout this period, the city's local groundwater complemented other sources.

The use of these multiple sources varies in response to the extremely variable climate, with surface water predominating in wet seasons and greater use of groundwater and reuse in dry periods. Local aquifer recharge has recently been introduced to store surplus water in wet periods, reducing evaporative losses from the surface reservoirs and increasing system yield (Murray et al. 2018).

However, while diversification of sources provides some additional resilience to inter-seasonal climate variability, the assured yield still depends on local natural recharge supplemented by surface water imports. Drought in 2015/2016 showed that despite tightly managed demand, additional supply was needed and attention turned once again to imports through the ENWC. Although capital and operating costs appear to be prohibitive, this would substantially reduce climate risk by diversifying to an unconstrained source.

In this difficult environment, available hydrological tools have consistently provided good estimates of the volumes of water available at different levels of assurance to guide system management. The technical analysis of the recharge and storage potential of the Windhoek aquifers has also provided the basis for implementation. Although the impacts of climate change on regional precipitation and Okavango River flows are uncertain (Hughes et al. 2011), Namibia's requirement is only around $2 \%$ of the total flow, suggesting that the objections of environmentalists in Botswana, the downstream riparian, are ill-founded.

The other long-term policy option is to break the "path dependence" since Windhoek was made the country's capital 130 years ago and promote economic development in Namibia's more humid northern region rather than increase the city's water supply. Absent such a radical policy shift, the incremental completion of the ENWC is a rational approach to making Windhoek's water supply more resilient since the scope for further savings through demand-side interventions is limited.

The city's century-long hydrological history and the acute nature of the water challenges that it faces have produced a good understanding of the options available to build systems that are resilient to the risks posed by long periods of multi-season drought. As a result, if adequate financial resources are available, the strategies already adopted to manage current climate variability will enable the city to meet its needs, even under conditions of climate change. 


\section{Beira, Mozambique: Sea Level Rise Will Compound Existing Challenges}

Like Windhoek, the Mozambican City of Beira faces many climate-related challenges given its location which is regularly hit by tropical storms. Established in 1890 as a port and regional railway hub on low-lying land at the mouth of the Pungwe River, urban water supply is difficult because fresh groundwater is very limited and the river's estuary is saline. While river flow is adequate to meet the city's needs, extensive saline intrusion, exacerbated by growing upstream water use, required its intake $80 \mathrm{~km}$ from the city to be moved further $20 \mathrm{~km}$ upstream. However, water quality problems continued for a nearby irrigation scheme whose intake the city had shared. While the intake could have been protected by building a weir downstream to obstruct tidal influx or storage dams upstream to maintain minimum dry season flows, these options were rejected on environmental grounds (NORAGRIC 1997).

While climate change impacts are obvious, hydrological analysis has characterized the salinity dynamics and helped to identify appropriate responses to the impact of increased water utilization and sea level rise. The immediate water management challenges have been well-characterized, and the priority is to coordinate responses to protect economic activity. However, in the longer term, the city's vulnerable location may require radical relocation rather than water management solutions.

\section{Polihali Dam and the Integrated Vaal River System: Sustaining a "Problemshed"}

In economic terms, the Integrated Vaal River System (IVRS) is the most important water resource development in Southern Africa. It supplies water to around 20 million people in a region that produces almost 50\% of South Africa's GDP and includes the country's administrative capital (Pretoria) as well as Johannesburg, its largest city. If its functioning is impaired by climate change impacts, the entire country will suffer.

The IVRS region lies across the watershed of the country's two largest rivers, the Orange and the Limpopo, which discharge into the Atlantic and Indian Oceans, respectively. By the 1960s, demand for water for domestic and economic purposes had outstripped the reliable flow of the main local source, the Vaal River, a tributary of the Orange River, which is also highly variable. A national policy review (South Africa 1970) recommended a system approach to identify and introduce new sources. This coincided with the emergence of new techniques to undertake the required analysis (Maass et al. 1962).

For four decades, system models guided decisions on expansion and operation (Basson and Van Rooyen 2001) that have successfully sustained water security in the expanding system. Throughout this period, the objective was to manage the extreme climate variability, with drought risk as the key metric since there was little useful information about potential climate change risks. 
An important element of the system is the Lesotho Highlands Water Project (LHWP), a multiphase scheme which diverts water that flows south from Lesotho in the Orange River, northward to its Vaal River tributary. In terms of a binational Treaty, South Africa uses Lesotho territory to discharge the waters closer to the centers of demand, with considerable cost-savings. Climate variability and change are addressed in the Treaty only insofar as provision for joint action in the event of force majeure, covering "disturbance due to an extreme hydrological or other natural event, including extreme drought, and affecting the delivery of water to South Africa." Similarly, while the 1998 Appraisal Report on Phase 1B of the project (which was successfully completed in 2002) makes no explicit mention of climate variability and change, it locates the purpose of the project as "reducing drought risk" in the South African system.

The LHWP's further phases are seen as low-risk, least-cost alternatives to augment the system's capacity. Phase 2, the construction of the Polihali Dam on another Orange River tributary, was included in the World Bank's "RDM study" (Cervigni 2015). As with the Mwache Project in Kenya (see above), the study considered whether alternative configurations might be less economically vulnerable if climate change reduced project performance.

Noting considerable climate uncertainty, the study suggested an alternative design could reduce the risk of financial losses due to climate change by up to $30 \%$. This only considered assumptions about water prices and demand and not the wider societal costs of supply failure, a conservative approach since, for many societies, higher water costs are preferable to the costs of unexpected supply failures (as is formally stated in the new Cape Town water strategy (Cape Town 2019)).

Subsequent studies concluded that the Polihali Dam would meet its intended delivery targets under a wide range of climate scenarios with deficits occurring only in the very driest 16 of 122 scenarios. The IVRS also illustrates the benefits of a "problemshed"-based analysis (Mollinga 2020) which encompasses the actual physical and institutional boundaries within which water is managed not simply an individual "watershed" approach. Whereas hydrological models are based on the natural "watersheds" before human activity intervenes, water management requires models that reflect the interaction between human activities and the natural system. The IVRS shows how hydrological tools can effectively be applied to manage substantial climate variability in complex multi-basin systems.

\section{Zambezi River Coordination: Drought Risks, Discount Rates, and Batoka Dam Hydropower}

The final case, the proposed Batoka Dam in the transnational Zambezi River Basin, illustrates the challenges of evaluating climate change's impacts in a complex system and uncertain economic and institutional context. In a basin that already suffers extreme climate events, the implications of climate change for hydropower expansion are a concern. Hydropower is the main source of electricity for the riparian 
countries and offers further opportunities to support their socioeconomic development. The Batoka Dam project illustrates the challenges of identifying adaptive approaches that optimize the benefits that hydropower can provide while minimizing the risk.

The history of Zambezi hydropower is as much about national and regional politics as hydrology or economics. Its potential was recognized early in the twentieth century, but it was only in the 1950s that it was decided to construct the Kariba Dam, creating what is still the world's largest dam reservoir by volume. Built by the Government of the Federation of Rhodesia and Nyasaland, Kariba's initial installed capacity of $1300 \mathrm{MW}$ was sufficient to meet the needs of the Federation. It was controversial because a smaller project could have been built on the Zambezi's Kafue tributary in Northern Rhodesia, closer to the mines that were the main centers of electricity demand. But political imperatives supported the larger project to reinforce the Federation although Northern Rhodesia, later Zambia, withdrew in 1963.

Mozambique's Cahora Bassa Dam, with an installed capacity of 2075 MW, had similar political drivers to Kariba; it used cheap electricity to reinforce the political relationship between the Portuguese colonial power and South Africa. This relationship was even shorter-lived - Mozambique became independent in 1975, just as Cahora Bassa was completed and the reservoir began to fill.

With the development in Zambia of the 900 MW Kafue Gorge Upper Dam and some smaller projects, there is now almost 5,000 MW of installed hydropower generation capacity in the basin with an average total energy production of around $30,000 \mathrm{GWh} /$ year, of which 23,000 is "firm energy," available at high reliability and very low cost, since most initial construction loans have long been repaid. This economic benefit of large water infrastructure is seldom accounted for although the resulting "path dependency" is often commented upon (Haasnoot et al. 2019).

The total energy production could be doubled to around $60,000 \mathrm{GWh} /$ year through the extension of existing facilities and the construction of new dams. This would meet most of the current electricity demand of the eight riparian states although optimal production will require hydrologically informed cooperation between operators. The resilience of new schemes to climate variability and change has come under particular scrutiny as international development finance institutions consider their financial viability.

While individual projects have been assessed in some detail, it is important to understand how they would function in a future system, which includes irrigation and urban uses, under conditions of climate change. At present, evaporation from the Kariba and Cahora Bassa lakes is by far the largest "consumptive use" of Zambezi water, accounting for $85 \%$ of the $12.5 \mathrm{~km}^{3}$ average "consumption"; all other uses (agriculture, urban, and industrial) account for just $1.9 \mathrm{~km} 3$, just $2 \%$ of the available runoff.

With the growth of population and economies, water consumption will reduce flows, impacting on hydropower production. A 2010 "Multi-Sector Investment Opportunity Analysis" (MSIOA) investigated the potential impacts of such new developments and the benefits for the riparian countries of coordinating their 
development plans, to reduce uncertainty about hydropower potential (World Bank 2010). The study included an economic assessment tool and considered possible climate change impacts. Its main finding was that coordinating investments and infrastructure operation could significantly increase the economic benefits compared to stand-alone project development. Beyond the hydrological uncertainties, the political challenge is to achieve an equitable sharing of the costs and benefits.

However, economic analysis is particularly challenging for investments such as water resource infrastructure which have a high initial cost but yield benefits over a very long period. The imputed value of long-term production depends heavily on assumptions about future prices as well as the "discount rate" applied in the analysis, and there is limited consensus about the appropriate approach, not least because the choice is usually determined by policy objectives (Fankhauser and Stern 2016) in which climate change adaptation strategies are not always adequately reflected.

These issues were illustrated in the analysis of Batoka in the 2015 RDM study (Cervigni 2015). The Batoka site is on the main stem of the Zambezi, downstream from Victoria Falls and upstream from Kariba. It has limited storage and will depend on natural river flows which, although moderated somewhat in the extensive wetlands of the upper catchment, are very variable and subject to drought, making it particularly vulnerable to climate change (Harrison and Whittington 2002).

In this context, the RDM study noted that:

"In drier futures, smaller facilities yield higher net benefits, as less investment is underutilized during the dry periods. In wetter futures, larger facilities that can better take advantage of high flow periods yield higher net benefits."

Batoka it found,

"shows significant sensitivity to climate change with up to a 33 percent decrease or a 15 percent increase in average power production.” (Cervigni 2015)

Over 30 years, the difference between the worst- and best-case scenarios was estimated at around US\$4 billion, in 2015 values, based on average energy prices in the Southern African Power Pool. But in a dry period, electricity prices would rise as all supplies would be reduced in a system that was dependent on hydropower. While in 2015 this effect was not yet evident because the region still had coal-fired alternatives, over the next five decades, coal-fired power will be constrained, and carbon taxes will increase its price, further supporting hydropower prices.

Even without these considerations, Batoka showed that "economics of projects of this type could be highly sensitive to the price of power" (Cervigni et al. 2015). Once again, it was emphasized that a project that was financially sensitive to climate change impacts was not necessarily financially vulnerable.

These economic studies are highly dependent on the discount rates chosen. The RDM study used a policy discount rate of 3\% for assessing social policy objectives. But for Batoka, both the MSIOA and the RDM analyses used a "finance discount" rate of $10 \%$ (World Bank 2010) to ensure adequate financial returns to repay loans. 
The danger is that using present-day markets to estimate long-run prices ignores the potential increase in the value of output as a result of climate change policies, devalues the long-term benefits of cooperation, and thus does not adequately reflect the policy goals of climate change mitigation.

A final gap in these attempts to integrate policies for climate resilience more effectively fully into hydrological and economic analysis has been the failure to consider the "water use efficiency" of energy generation in the Zambezi Basin. Presently, over $10 \%$ of the Zambezi's flow is lost to evaporation from the two large hydropower reservoirs. Full development of the basin will not require the significant expansion of storage to manage hydrological variability, and the proposed cascade of three dams in the lower Zambezi will benefit from the hydrological security provided by the Kariba and Cahora Bassa reservoirs upstream. While the MSIOA notes with concern that the output of those projects could vary between $+9 \%$ and $-13 \%$ by 2100 (World Bank 2010), it makes no allowance for value inherent in increasing "water use" efficiency by increasing the energy produced per unit of water.

These analyses of the Batoka Dam and the broader strategies to ensure optimum management of the Zambezi Basin's waters show that the challenges of assessing the economic benefits and risks of large water investments are at least as complex as those of managing the hydrological uncertainties.

\section{Discussion: Principles to Guide Adaptation under Uncertainty}

The cases presented illustrate the contexts within which major water resource investment decisions are taken and the limited contribution that can be made by emerging climate change science beyond the charting of the range of future uncertainty. Nevertheless, the focus on potential climate change impacts does provide useful guidance for the planners, developers, and operators of major water resource infrastructure working in "difficult hydrologies."

\section{Principles}

From these cases, some general principles can be identified that could help water resource managers to develop coherent adaptive strategies for the projects or systems for which they are responsible and assist them in communicating their approaches to their wider communities. In addition, some more operational priorities emerge that merit mention.

\section{Uncertainty}

Perhaps the most important principle to emerge from the cases is that uncertainty remains the dominant feature of potential climate change impact on water resource projects. This uncertainty must be recognized and reflected in analytical approaches, strategy development, and project design. Uncertainty does not mean that stochastic 
methods cannot be used to detect - and project - trends. For instance, where projections of precipitation are made using multiple GCMs and the range of future uncertainties can be constrained, stochastic methods are already usefully applied. More serious challenges arise where relevant variables are not well understood or constrained as is the case with modeling future rainfall-runoff in conditions where both land cover and precipitation intensities are both poorly understood.

\section{Precautionary}

The precautionary principle is usually understood to constrain developments until their impacts are understood. In the climate change context, a precautionary approach will ensure that decisions are taken in time to address possible future contingencies. This is explicitly stated in Cape Town's post-disaster water strategy which commits to make new investments which will not be used unless there is a dry period in which they are needed. This reflects the high costs imposed on the wider society by supply failure. Projects with lengthy implementation periods such as the IVRS augmentations should be implemented on a precautionary basis to avoid inefficient crisis responses that characterized many water sector investments. A precautionary approach would also introduce supply restrictions earlier rather than later although political resistance is always a factor in this - recent extreme power restrictions in Zimbabwe resulted, in part, from earlier decisions to continue generating at full capacity at Kariba, contrary to drought operating rules.

\section{Path Dependence}

A concern frequently raised about water resource developments of all kinds is that they commit their societies to particular development paths and close off other options. The difficulty with these discussions is that they frequently involve larger political issues about which there is little consensus. In large measure, Windhoek's current challenges are the result of century-old colonial spatial planning decisions; the option of refocusing economic development in a more propitious location is an important alternative. Similarly, South Africa's IVRS reflects the fact that the mining economy promoted extensive development in a location with limited water resources and that coastal areas would be easier to serve. Beira's location, which also served colonial objectives, is very vulnerable to current climate, and vulnerabilities will be aggravated by climate change. But these are not issues on which water managers can determine policy. At best, they can ensure that the concerns and constraints are well understood and thus influence wider development policy debates.

\section{Flexibility}

In response to uncertainty about future trends, it is helpful if strategies to meet future needs are sufficiently flexible to accommodate different futures. This principle has already been explicitly adopted in a number of the case study projects: Cape Town has identified a range of options that could rapidly be implemented in the event of a "step change" in climate; the ENCW scheme serving Windhoek can be implemented in a sequence of steps. Similarly, each step in the past and future development of South Africa's IVRS involved a choice from a set of different options. 


\section{System-Wide Approaches and Problemsheds}

The importance of conceptualizing and operating linked infrastructure as a system rather than as individual units brings many benefits. The values of these benefits are explicitly determined in the Zambezi Basin MSIOA but are also evident in the IVRS, Windhoek, and, at a nascent stage, Mombasa and Cape Town's new strategy.

\section{Linkages}

The linkage of different sources and demand centers provides a variety of resilience benefits that can greatly assist adaptation to changing climate conditions. A benefit that could be achieved by operating Zambezi hydropower as a coordinated system is that extreme events are often not correlated. While in the south Victoria Falls and Kariba were running dry, Cahora Bassa which draws more resources from the north had to open its flood gates to manage inflows. South Africa's IVRS has already demonstrated that multiple sources provide greater assured yields than the sum of their "stand-alone" yields and Windhoek's situation is similar. Proposals for Kenya's Mwache Dam to form part of an integrated bulk system would replicate this approach.

\section{Diversification}

Diversification of sources provides further important resilience benefits and should be a guiding principle for climate change adaptation. Windhoek's surface water/ groundwater mix has enabled it to withstand repeated drought crises. Cape Town's recent experience highlighted the risk of relying solely on surface water supplies, which although linked all derived their inflow from a single small catchment area. Alternative sources had not been developed because, individually, their unit costs were higher, but this calculation omitted consideration of the value of additional reliability that could be gained from diversification. Care must be taken, however, to ensure that apparently diversified sources are not correlated. Thus, while reuse is a useful option, it depends on the availability of wastewater which, in crisis situations, may be constrained.

\section{Storage Vs Yield}

It is widely recognized that storage is an integral element of any substantial water resource system, crucial to ensure adequate flows in dry seasons. However, it is often considered solely as part of river management infrastructure. Both Windhoek and the IVRS use strategic storage fed slowly by wet season surpluses from external sources to build a reserve that can be drawn down to provide a guaranteed supply during dry periods. This contributes significantly to their reliance against drought and other climate impacts at lower cost than would be required for the development of a new source.

\section{Valuing Resilience and Reliability}

One of the features of both water and power projects in Southern and Eastern Africa is how little recognition is given to the financial and economic benefits of reliability 
and resilience of supply. This was forcefully illustrated by the economic losses suffered by Cape Town due to 3 years of water restrictions. But the economies of countries dependent on Zambezi hydropower have also been significantly constrained by the power cuts and rationing, and Windhoek's economic activity has been curtailed by water shortages. There is a need for more nuanced analysis of the funding of schemes that enhance resilience and reliability of supply since these values are often not included in user charges and benefit a wider public than the direct users.

\section{Operational Priorities}

\section{Institutional Capacity Will be Critical}

Given the intensification of hydrological analysis and decision-making, water management institutions will have to ensure that they have the capabilities to respond to the emerging challenges. This will require appropriate structures as well as the development and retention of the specialist skills, often in collaboration with specialized institutions of higher education.

\section{Adequate Finance Is Required}

In all the water supply cases, current investment has been insufficient to achieve resilience to current climate variability. While this is often viewed as a problem that can be resolved by establishing effective markets for water (and also to power), the benefits of assured supplies spill far beyond the direct users to the wider society although they may only be fully realized in the longer term. This means that the full value of the water project outputs cannot be captured by prices alone and different financial arrangements are required that reflect the long-run economic benefits of secure supplies. Where water projects, notably hydropower, directly mitigate climate change by reducing greenhouse gas emissions, this should be reflected in financial terms. Current "green finance" proposals will only be of assistance if loan conditions address these structural constraints.

\section{Communication to Achieve Sufficient Consensus}

Water resource development occurs to a greater or lesser extent in the public domain and is thus subject to public scrutiny and political decision. One of the challenges faced by sector managers is that they address complex issues about which public perceptions may differ widely. Water management institutions need to develop and sustain communication with their stakeholder communities to ensure their support for demand-side interventions as well as for investments on the supply side.

\section{Information for "Dynamic Stationarity"}

The dynamic nature of hydrological systems under climate change means that analysis will no longer rely on standard sets of reference data from a fixed time period. The values of many hydrological variables will be changing in unpredictable ways that will require hydrological data to be updated on a regular basis. This will 
require an intensification of data collection and management. As one group of commentators remarked, "in a nonstationary world, continuity of observations is critical” (Milly et al. 2008).

\section{Conclusions}

The principles that emerged from this review support the initial hypothesis that adaptation to climate change in the water and hydropower sector will best be achieved by following strategies that address current climate variability. All of the principles enunciated are equally appropriate to current climate variability or climate change.

The proviso introduced by including climate change is that such interventions should recognize that uncertainties under future climate change are likely to be greater than at present. This reinforces the need for options that allow greater flexibility of approach, but it also highlights the need for a precautionary approach that will see interventions made earlier rather than later, as Cape Town found to its cost.

The idea that interventions should be made sooner rather than later will often meet opposition because it will be seen to reinforce current development trajectories and path dependence. The reason that alternative trajectories are not followed is usually that they are constrained by politics and economics. Even if the intent is to allow economic and social disruption to drive new trajectories, creating water and power crises is unlikely to create the conditions for change. Given the challenges posed by climate change, deliberate disruption of societies and economies is a high risk strategy with little certainty about the likely outcomes.

One consistent finding is that the challenges of planning, implementing, and operating large water resource schemes under difficult hydrologies will become more complex as climate change impacts intensify. While traditional hydrological tools can continue to be used, "dynamic stationarity" will require more intensive data collection, more frequent reviews and runs of models, and greater effort to communicate the findings and their implications to the wider community whose consent, trust, and support will be required for decisions. In most countries, this will require more capable organizations, better funded, staffed, and equipped than at present.

In all of this, the primary constraint to adapting to the impacts of climate change by building more resilient and less vulnerable systems will continue to be financial. A particular challenge for the water sector's practitioners will thus be to persuade their communities that additional support for planning and managing their countries' water will insure them against the larger costs of water and power supply failures.

\section{References}

Adler RF, Gu G, Sapiano M, Wang JJ, Huffman GJ (2017) Global precipitation: means, variations and trends during the satellite era (1979-2014). Surv Geophys 38(4):679-699 
Archer E, Landman W, Malherbe J, Tadross M, Pretorius S (2019) South Africa's winter rainfall region drought: a region in transition? Clim Risk Manag 25:100188

Bailey AK, Pitman WV (2016) Water resources of South Africa, 2012 Study (WR2012), WR2012 study executive summary. WRC Report TT, 683. Water Research Commission, Gezina, p 16

Basson MS, Van Rooyen JA (2001) Practical application of probabilistic approaches to the management of water resource systems. J Hydrol 241(1-2):53-61

Blochl et al (2019) Twenty-three unsolved problems in hydrology (UPH) - a community perspective. Hydrol Sci J 64(10):1141-1158. https://doi.org/10.1080/02626667.2019.1620507

Brekke LD, Kiang JE, Olsen JR, Pulwarty RS, Raff DA, Turnipseed DP, Webb RS, White KD (2009) Climate change and water resources management - a federal perspective: U.S. Geological Survey Circular 1331, 65 p. Also available online at http://pubs.usgs.gov/circ/1331/

Briscoe J (2010) Practice and teaching of American water management in a changing world. J Water Resour Plan Manag

Cape Town (2019) Our shared water future: Cape Town's water strategy, City of Cape Town

Cervigni R, Liden R, Neumann JE, Strzepek KM (2015) Enhancing the climate resilience of Africa's infrastructure: the power and water sectors. Overview booklet. World Bank, Washington, DC

Chahine M (1992) The hydrological cycle and its influence on climate. Nature 359:373-380. https://doi.org/10.1038/359373a0

Chan JC (2006) Comment on "Changes in tropical cyclone number, duration, and intensity in a warming environment". Science 311(5768):1713-1713

Conway D (2005) From headwater tributaries to international river: observing and adapting to climate variability and change in the Nile basin. Glob Environ Chang 15(2):99-114

Fankhauser S, Stern N (2016) Climate change, development, poverty and economics (presented at) The State of Economics, the State of the World conference. World Bank, Washington, DC

Foster S, Eichholz M, Nlend B, Gathu J (2020) Securing the critical role of groundwater for the resilient water-supply of urban Africa. Water Policy 22(1):121-132

Gangrade S, Kao SC, Naz BS, Rastogi D, Ashfaq M, Singh N, Preston BL (2018) Sensitivity of probable maximum flood in a changing environment. Water Resour Res 54(6):3913-3936

Giorgi F, Raffaele F, Coppola E (2019) The response of precipitation characteristics to global warming from climate projections. Earth Syst Dynam 10:73-89. https://doi.org/10.5194/esd-1073-2019

Greve et al (2019) The aridity index under global warming. Environ Res Lett 14:124006

Grey D, Sadoff CW (2007) Sink or swim? Water security for growth and development. Water Policy 9(6):545-571

Haasnoot M, van Aalst M, Rozenberg J, Dominique K, Matthews J, Bouwer LM, Kind J, Poff NL (2019) Investments under non-stationarity: economic evaluation of adaptation pathways. Clim Change: $1-13$

Harrison GP, Whittington HBW (2002) Susceptibility of the Batoka gorge hydroelectric scheme to climate change. J Hydrol 264(1-4):230-241

Hegerl GC, Brönnimann S, Cowan T, Friedman AR, Hawkins E, Iles C, Müller W, Schurer A, Undorf S (2019) Causes of climate change over the historical record. Environ Res Lett 14 (12): 123006

Herold N, Behrangi A, Alexander LV (2017) Large uncertainties in observed daily precipitation extremes over land. J Geophys Res-Atmos 122:668-681

Hughes DA, Kingston DG, Todd MC (2011) Uncertainty in water resources availability in the Okavango River basin as a result of climate change. Hydrol Earth Syst Sci 15(3)

Hüttl RF, Bens O, Bismuth C, Hoechstetter S (2016) Society-Water-Technology: a critical appraisal of major water engineering projects. Springer Nature, p 295

Knutson T, Camargo SJ, Chan JC, Emanuel K, Ho CH, Kossin J, Mohapatra M, Satoh M, Sugi M, Walsh K, Wu L (2020) Tropical cyclones and climate change assessment: Part II: projected response to anthropogenic warming. Bull Am Meteorol Soc 101(3):E303-E322 
Kraemer BM, Seimon A, Adrian R, McIntyre PB (2020) Worldwide lake level trends and responses to background climate variation. Hydrol Earth Syst Sci 24(5):2593-2608

Loucks DP, Van Beek E (2017) Water resource systems planning and management: an introduction to methods, models, and applications. Springer

Maass A, Hufschmidt MA, Dorfman R, Thomas HA Jr, Marglin SA, Fair GM (1962) Design of water-resource systems: new techniques for relating economic objectives, engineering analysis, and governmental planning. Harvard University Press, Cambridge, Mass

Malherbe J, Engelbrecht FA, Landman WA, Engelbrecht CJ (2012) Tropical systems from the Southwest Indian Ocean making landfall over the Limpopo River basin, southern Africa: a historical perspective. Int J Climatol 32(7):1018-1032

Matalas NC (1997) Stochastic hydrology in the context of climate change. Clim Chang 37(1):89101

Milly PCD, Betancourt J, Falkenmark M, Hirsch RM, Kundzewicz ZW, Lettenmaier DP, Stouffer RJ (2008) Stationarity is dead: whither water management? Earth 4:20

Mollinga PP (2020) Knowledge, context and problemsheds: a critical realist method for interdisciplinary water studies. Water Int. https://doi.org/10.1080/02508060.2020.1787617

Moss ME, Tasker GD (1987) The role of stochastic hydrology in dealing with climatic variability. In: The influence of climate change and climatic variability on the hydrologic regime and water resources (Proceedings of the Vancouver symposium, August 1987), vol 168. IAHSPubl, pp 201-207. Accessed at http://hydrologie.org/redbooks/a168/iahs_168_0201.pdf

Muller M (2018) Lessons from Cape Town's drought. Nature 559(7713):174-176

Muller M, Biswas A, Martin-Hurtado R, Tortajada C (2015) Built infrastructure is essential. Science 349(6248):585-586

Murray R, Louw D, van der Merwe B, Peters I (2018) Windhoek, Namibia: from conceptualising to operating and expanding a MAR scheme in a fractured quartzite aquifer for the city's water security. Sustaina Water Resour Manage 4(2):217-223

NORAGRIC (1997) Environmental assessment of the Mozambique National Water Development Project. World Bank. Accessed at http://documents1.worldbank.org/curated/en/ 165791468779949188/pdf/multi-page.pdf

Pillay MT, Fitchett JM (2019) Tropical cyclone landfalls south of the tropic of Capricorn, southwest Indian Ocean. Clim Res 79(1):23-37

Sidibe M, Dieppois B, Mahé G, Paturel JE, Amoussou E, Anifowose B, Lawler D (2018) Trend and variability in a new, reconstructed streamflow dataset for west and Central Africa, and climatic interactions, 1950-2005. J Hydrol 561:478-493

South Africa (1970) Commission of enquiry into water matters, Report of the commission of enquiry Into water matters, vol 34. Government Printer, Pretoria

Strzepek K, McCluskey A, Boehlert B, Jacobsen M, Fant C IV (2011) Climate variability and change: a basin scale indicator approach to understanding the risk of climate variability and change: to water resources development and management. World Bank, Washington, DC, pp 1139

Trelease FJ (1977) Climatic change and water law. In: National research council, climate, climatic change, and water supply. National Academies, Washington, DC

Trenberth KE (2011) Changes in precipitation with climate change. Clim Res 47(1-2):123-138

Ukkola AM, De Kauwe MG, Roderick ML, Abramowitz G, Pitman AJ (2020) Robust future changes in meteorological drought in CMIP6 projections despite uncertainty in precipitation. Geophys Res Lett e2020GL087820

Vaze J, Post DA, Chiew FHS, Perraud JM, Viney NR, Teng J (2010) Climate non-stationarityvalidity of calibrated rainfall-runoff models for use in climate change studies. J Hydrol 394(34):447-457

Venter ZS, Cramer MD, Hawkins HJ (2018) Drivers of woody plant encroachment over Africa. Nat Commun 9(1):1-7

Vogel RM (2017) Stochastic watershed models for hydrologic risk management. Water Secur 1:28 35 
Woodhouse P, Muller M (2017) Water governance - an historical perspective on current debates. World Dev 92:225-241

World Bank (2010) The Zambezi River basin a multi-sector investment opportunities analysis (Volume 1) Summary report. World Bank, Washington, DC

World Bank (2018a) Assessment of the state of hydrological services in developing countries. World Bank, Washington, DC

World Bank (2018b) Economywide and distributional impacts of water resources development in the coast region of Kenya: implications for water policy and operations. World Bank, Washington, DC

Zareian MJ, Eslamian S, Gohari A, Adamowski JF (2017) The effect of climate change on watershed water balance. In: Mathematical advances towards sustainable environmental systems. Springer, Cham, pp 215-238

Open Access This chapter is licensed under the terms of the Creative Commons Attribution 4.0 International License (http://creativecommons.org/licenses/by/4.0/), which permits use, sharing, adaptation, distribution and reproduction in any medium or format, as long as you give appropriate credit to the original author(s) and the source, provide a link to the Creative Commons license and indicate if changes were made.

The images or other third party material in this chapter are included in the chapter's Creative Commons license, unless indicated otherwise in a credit line to the material. If material is not included in the chapter's Creative Commons license and your intended use is not permitted by statutory regulation or exceeds the permitted use, you will need to obtain permission directly from the copyright holder.

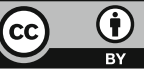

